\title{
DOI: 10.5433/1679-0359.2011v32Suplp1989 \\ Plasma sanguíneo desidratado na recuperação de leitões leves ao desmame: desempenho zootécnico, perfil hematológico, freqüência de diarréia e viabilidade econômica
}

\section{Spray-dried plasma in the recovery of light piglets at weaning: production performance, blood profile, diarrhea frequency and economic viability}

\author{
Danyel Bueno Dalto ${ }^{1 *}$; Caio Abércio da Silva²; Ana Maria Bridi²; David Fernandes \\ Gavioli $^{1}$; Eduardo Raele de Oliveira ${ }^{1}$; Roberta Abrami Monteiro da Silva ${ }^{3}$; Marina \\ Avena Tarsitano4; Álvaro Henrique de Sousa Altmann'; Débora Barbosa Braz"; \\ Renata Katsuko Takayama Kobayashi ${ }^{5}$; Emerson José Venâncio ${ }^{6}$
}

\section{Resumo}

\begin{abstract}
O objetivo desse trabalho foi avaliar o desempenho, perfil hematológico, freqüência de diarréia e potencial econômico de uso do plasma sanguíneo desidratado (PSD) na dieta de leitões desmamados com baixo peso, aos 21 dias de idade. Foram utilizados 72 leitões, sendo 48 machos castrados e 24 fêmeas (PenArLan) com idade média inicial de 21 dias. O delineamento experimental foi de blocos ao acaso, com 4 tratamentos e 6 repetições por tratamento (cada baia com dois machos e uma fêmea foi considerada uma repetição). Os tratamentos foram: T1 - animais pesados ao desmame, sem suplementação; T2 - animais leves ao desmame, suplementados com 10g/animal/dia de PSD; T3 - animais leves ao desmame, suplementados com 20g/animal/dia de PSD; T4 - animais leves ao desmame, sem suplementação. O PSD (10 e 20g/ animal/dia) foi fornecido diretamente no cocho três vezes ao dia. Aos 35 e 70 dias de idade os leitões foram submetidos a coleta de sangue, sendo utilizado 8 animais de cada tratamento. Diariamente foi realizada a avaliação da freqüência de diarréia. Foi verificada diferença para conversão alimentar $(P<0,05)$ no período de tratamento compreendido entre 21 a 49 dias de idade e para o período experimental total (21 a 70 dias de idade) com vantagem para o T3. Os valores iniciais de uréia plasmática apresentaram diferença $(\mathrm{P}<0,01)$ com vantagem para o $\mathrm{T} 1$, no entanto os valores finais mostraram-se semelhantes. Não houve diferença $(\mathrm{P}>0,05)$ para freqüência de diarréia. Houve um melhor resultado na análise econômica, apontando vantagem para o T3 em relação ao custo da ração nos períodos compreendidos entre 21 a 35 dias, 36 a 49 dias e entre 21 a 49 dias de idade. Considerando todo o período experimental (21 a 70 dias de idade) o T3 apresentou melhor índice de eficiência econômica e de custo médio.
\end{abstract}

Palavras-chave: Plasma sanguíneo desidratado, uréia, diarréia, eficiência econômica

\footnotetext{
1 Discentes de Mestrado do Programa de Pós-Graduação em Ciência Animal, Centro de Ciências Agrárias, Universidade Estadual de Londrina/CCA/UEL, Londrina, PR. E-mail: danyelbd@hotmail.com ; davidgazioli@hotmail.com; duraele@yahoo.com.br; altzoo@hotmail.com

2 Profs. Drs. do Dept ${ }^{\circ}$ de Zootecnia/CCA/UEL, Londrina, PR. E-mail: ambridi@uel.br; casilva@uel.br

3 Discentes de Doutorado do Programa de Pós-Graduação em Ciência Animal/CCA/UEL, Londrina, PR. E-mail: ro_abrami@ hotmail.com; marina_avena@yahoo.com.br

4 MCassab Comércio e Indústria Ltda. E-mail: debora.braz@mcassab.com.br

5 Prof $^{\mathrm{a}} \mathrm{Dr}^{\mathrm{a}}$ do Dept ${ }^{\mathrm{o}}$ de Microbiobiogia, CCB/UEL, Londrina, PR. E-mail: kobayashirkt@uel.br

6 Prof. Dr. do Dept ${ }^{\circ}$ de Biologia/CCB/UEL, Londrina, PR. E-mail: emersonj@uel.br

* Autor para correspondência
} 


\begin{abstract}
The aim of this research was to evaluate the effects of spray-dried plasma (SDP) on the performance, hematological profile, diarrhea frequency and economic viability of this ingredient in diets for light piglets at weaning, with 21 days of age. The trial was done using 72 pigs, 48 castrated male and 24 female (PenArLan), with an initial age of 21 days. The experimental design consisted of randomized blocks, with 4 treatments and 6 repetitions (each pen with two males and one female was considered a repetition). The treatments were: T1 - heavy weight weaned pigs, without supplementation; T2 light weight weaned pigs, supplemented with $10 \mathrm{~g} /$ animal/day of SDP; T3 - light weight weaned pigs, supplemented with $20 \mathrm{~g} /$ animal/day of SDP; T4- light weight weaned pigs, without supplementation. The SDP were fed daily directly at the feeder three times per day. At 35 and 70 days old piglets were subjected to blood collection, and 8 animals in each treatment were used. Daily evaluation was made of diarrhea frequency. There was difference to feed:gain $(\mathrm{P}<0,05)$ considering the period of 21 to 49 days of age and total period (21-70 days of age), with advantage to T3. The initial value for plasmatic urea was higher $(\mathrm{P}<0,01)$ to pigs of $\mathrm{T} 1$ but the final titles were similar. There were no differences $(\mathrm{P}>$ $0,05)$ on frequency of diarrhea. There were differences in feed cost with advantage to T3 in the period of 21 to $35 ; 36$ to 49 and 21 to 49 days of age. In total period (21 to 70 days of age) T3 showed the best index of economic efficiency.
\end{abstract}

Key words: Spray dried plasma, urea, diarrhea, economic efficiency

\section{Introdução}

A produção de 30 leitões desmamados por porca por ano atualmente é uma realidade em diversas unidades produtoras (DALTON; SOUZA; SALUM, 2008). Este cenário, todavia, tem determinado uma piora no peso ao nascer e ao desmame, características inversamente relacionadas com o tamanho da leitegada (MORÉS, 1993). Segundo Holanda et al. (2005), na avaliação dos fatores que contribuem para o peso ao desmame, apenas o número de nascidos vivos, e não o número de nascidos totais deve ser considerado, uma vez que maior número de nascidos vivos promove aumento no peso médio da leitegada, mas reduz o peso médio individual. Para cada leitão nascido a mais na leitegada há uma redução no peso individual de $35 \mathrm{~g}$, em média, além de aumentar a proporção de leitões leves (com menos de 1,0kg). O aumento da leitegada de 7-9 para 13 leitões resulta em 0,2 leitões fracos para cada leitão adicional. Para leitegadas com mais de 13 leitões, cada leitão extra resulta em 0,7 leitões leves a mais (LE DIVIDICH, 1999).

A preocupação com a minimização de perdas e otimização do desenvolvimento de leitões leves ao desmame tem exigido um incremento qualitativo nas dietas ao desmame. O tipo de proteína na ração de leitões tem grandes conseqüências no consumo da ração, no ganho de peso, na digestibilidade do nitrogênio e nas atividades das enzimas pancreáticas (MAKKINK et al., 1994a, 1994b, PEINIAU; AUMAITRE; LEBRETON, 1996). Desse modo, têm-se buscado alternativas como o fornecimento de rações que contenham tanto fontes protéicas de origem animal quanto fontes protéicas de origem vegetal (GATTÁs et al., 2008).

O plasma sanguíneo desidratado (PSD) é uma excelente fonte de proteínas de alto valor nutricional para leitões desmamados, além de possuir uma ótima relação de aminoácidos e alto nível de proteínas globulares (incluindo imunoglobulinas) que estimulam o crescimento e consumo de ração durante a fase crítica do pósdesmame (CROMWELL, 2006). Pesquisas com leitões desmamados aos 21 dias indicam que o uso de PSD nas dietas aumenta a secreção de enzimas digestivas, melhora a integridade do epitélio intestinal e aumenta a digestão, absorção e utilização dos nutrientes, especialmente na 
primeira semana após o desmame (CAMPBELL, 2003). Depréz et al. (1996) e Nollet et al. (1999) justificaram ainda a utilização de PSD pela capacidade de suas glicoproteínas reduzirem a adesão de $E$. coli aos enterócitos. Esses autores observaram diminuição no número de E.coli nas fezes de suínos alimentados com dietas contendo PSD diante de uma infecção induzida. Segundo Pierce et al. (2005), é provável que a IgG previna a adesão de patógenos, como a $E$. coli, no epitélio intestinal.

No entanto, há algumas limitações quanto ao uso de PSD para leitões. A principal é o alto custo quando comparado a outras fontes protéicas de origem animal, como a farinha de peixe e o soro de leite.

Nesse sentido, o objetivo desse experimento foi avaliar os efeitos do PSD fornecido diretamente no cocho sobre o desempenho, perfil hematológico, freqüência de diarréia e eficiência econômica do plasma sanguíneo desidratado na alimentação de leitões desmamados leves aos 21 dias de idade.

\section{Material e Métodos}

O experimento foi conduzido no Setor de Suinocultura da Fazenda Escola da Universidade Estadual de Londrina. As análises foram realizadas no Laboratório de Patologia Clínica da Universidade Estadual de Londrina. Foram utilizados 72 animais da linhagem PenArLan, sendo 48 machos castrados e 24 fêmeas. A média de idade no início do experimento foi de 21 dias. Os pesos iniciais foram divididos em dois grupos, sendo um grupo com pesos iniciais entre 4,5 e $5,5 \mathrm{~kg}$ (animais leves) e outro com pesos iniciais entre 5,6 e $6,5 \mathrm{~kg}$ (animais pesados). Os animais foram alojados em baias de alvenaria e piso compacto com $3 \mathrm{~m}^{2}$, sendo a baia composta por três animais, dois machos castrados e uma fêmea, totalizando 24 baias, onde receberam água e ração à vontade durante todo o período experimental cuja duração foi de 49 dias.

As rações experimentais foram formuladas definindo três fases, pré-inicial I (21 a 35 dias de idade), pré-inicial II (36 a 49 dias de idade) e inicial (50 a 70 dias de idade).

Os ingredientes, a composição percentual e os valores analisados das rações experimentais encontram-se na Tabela 1.

O suplemento protéico, vitamínico e mineral utilizado na ração pré-inicial I (PS 400®) apresentava na sua formulação soro de leite, glúten de milho, proteína texturizada de soja, levedura de cana, milho pré-gelatinizado, açúcar e lactose. O suplemento PS $250 \AA$ utilizado na elaboração da ração pré-inicial II apresentava os mesmos ingredientes com exceção do glúten de milho. O suplemento Inicial $40 \AA$ utilizado na elaboração da ração inicial era composto por levedura de cana, além dos componentes listados na Tabela 1. O PSD comercial continha as seguintes especificações: plasma sanguíneo suíno em pó $(98,181 \%)$, vitamina E e DLmetionina, sendo composta por $77,7 \%$ de $\mathrm{PB}$, $18.000 \mathrm{mg}$ de metionina e $5 \mathrm{mg}$ de vitamina $\mathrm{E}$, sendo seu fornecimento efetuado diretamente no cocho (duas vezes ao dia).

Os animais foram submetidos aos seguintes tratamentos experimentais:

T1 - animais pesados, não suplementados com PSD;

T2 - animais leves, suplementados com 10g/ animal/dia de PSD;

T3 - animais leves, suplementados com 20g/ animal/dia de PSD;

T4 - animais leves, não suplementados com PSD. 
Tabela 1. Composição percentual, química e energética das rações experimentais.

\begin{tabular}{lccc}
\hline Ingredientes (\%) & Pré- Inicial I (PS 400) & Pré- Inicial II (PS 250) & Inicial (Inicial 40) \\
\hline Milho & 43 & 50 & 66 \\
Farelo de soja & 17 & 25 & 30 \\
Suplemento suíno fases $1,2,3$ & 40 & 25 & 4 \\
Total & 100 & 100 & 100 \\
Valores analisados & & & \\
Proteína Bruta (\%) & 19,73 & 18,85 & 19,76 \\
Extrato Etéreo (\%) & 2,94 & 2,58 & 2,54 \\
Fibra Bruta (\%) & 2,15 & 2,63 & 3,04 \\
Matéria Mineral (\%) & 4,38 & 4,14 & 5,01 \\
Cálcio (\%) & 0,63 & 0,64 & 0,72 \\
Fósfora total (\%) & 0,56 & 0,60 & 0,45 \\
Energia Metab. (Kcal/kg) & 3.296 & 3.345 & 3.238 \\
Lisina total (\%) & 1,41 & 1,37 & 1,14 \\
Metionina total (\%) & 0,50 & 0,46 & 0,33 \\
\hline
\end{tabular}

${ }^{1}$ Composição do suplemento pré-inicial I: PB (21,00 \%), EE (3,70 \%), FB (1,20\%), MM (7,10 \%), EM (3.121 kcal), L-lisina (20,10 mg), DL-metionina (8,34 mg), L-triptofano (3,16 mg), L-treonina (13,32 mg), Ca (14,50 g), P (9,20 g), $\mathrm{Na}$ (5,20 g), Se (0,92 mg), Fé (436,00 mg), Cu (500,00 mg), Mn (162,00 mg), Zn (7,50 mg), ácido glutâmico (7,74 $\mathrm{mg}$ ), glutamina (2,00 mg), ácido butírico (54,60 mg), vit. A (25.040 UI), vit. D3 (6.260 UI), vit. E (125,30 mg), vit. B1 (4,70 mg), vit. B2 (15,65 mg), vit. B6 (6,26 mg), vit. B12 (62,60 mcg), vit. K3 (1,57 mg), niacina $(81,90 \mathrm{mg})$, ácido pantoténico $(34,50 \mathrm{mg})$, biotina $(0,25 \mathrm{mg})$, ácido fólico $(2,70 \mathrm{mg})$, colistina $(100,00 \mathrm{mg})$, BHA $(6,15 \mathrm{mg})$, BHT $(18,45 \mathrm{mg})$, etoxiquin $(18,45 \mathrm{mg})$, palatabilizantes $(375,00 \mathrm{mg})$, aromat. Leite $(62,11 \mathrm{mg})$, aromat. Baunilha $(62,11$ $\mathrm{mg})$, acidificante $(20, .000 \mathrm{mg})$, lactose $(212,50 \mathrm{Mg})$;

2 Composição do suplemento pré-inicial II: PB (13,00 \%), EE (2,70 \%), FB (1,00\%), MM (8,60 \%), EM (3.190 kcal),L-lisina (21,06 mg), DL-metionina (8,70 mg), L-triptofano (2,65 mg), L-treonina (12,93 mg), Ca (22,30 g), P (12,30 g), $\mathrm{Na}(6,65 \mathrm{~g}), \mathrm{Se}(1,43 \mathrm{mg})$, Fé (746,00 mg), Cu (800,00 mg), Mn (252,00 mg), Zn (8,80 mg), ácido glutâmico (5,23 mg), glutamina (2,40 mg), ácido butírico ( $86,40 \mathrm{mg})$, vit. A (40.000 UI), vit. D3 (10.000 UI), vit. E (200,00 mg), vit. B1 (7,50 mg), vit. B2 (25,00 mg), vit. B6 (10,00 mg), vit. B12 (100,00 mcg), vit. K3 (2,50 mg), niacina (128,00 $\mathrm{mg}$ ), ácido pantoténico $(55,20 \mathrm{mg})$, biotina $(0,32 \mathrm{mg})$, ácido fólico $(4,20 \mathrm{mg})$, colistina $(160,00 \mathrm{mg})$, BHA $(10,00 \mathrm{mg})$, BHT $(30,00 \mathrm{mg})$, etoxiquin $(30,00 \mathrm{mg})$, palatabilizantes $(600,00 \mathrm{mg})$, aromat. Leite $(98,28 \mathrm{mg})$, aromat. Baunilha $(98,28 \mathrm{mg})$, acidificante $(24.000 \mathrm{mg})$, lactose $(168,00 \mathrm{mg})$;

${ }^{3}$ Composição do suplemento Inicial: L-lisina (29,66 mg), DL-metionina (6,13 mg), L-treonina (8,06 mg), Ca (155,60 g), P (19,20 g), Na (43,80 g), Se (7,00 mg), Fé (3,066 mg) mg), Cu (4,382 mg), Mn (1,563 mg), Zn (40,02 mg), ácido butírico (75,48 mg), vit. A (200.000 UI), vit. D3 (50.000 UI), vit. E (1.250 mg), vit. B1 (37,50 mg), vit. B2 (125,00 $\mathrm{mg})$, vit. B6 (50,00 mg), vit. B12 (500,00 mcg), vit. K3 (12,50 mg), niacina $(625,00 \mathrm{mg})$, ácido pantoténico $(276,00$ $\mathrm{mg}$ ), biotina (1,25 mg), ácido fólico (20,00 mg), colistina (1.000 mg), BHA (31,45 mg), BHT (94,35 mg), etoxiquin $(94,35 \mathrm{mg})$, palatabilizantes $(3.749 \mathrm{mg})$, aromat. Leite $(85,85 \mathrm{mg})$, aromat. Baunilha $(85,85 \mathrm{mg})$.

Fonte: Elaboração dos autores.

A inclusão do PSD se manteve durante as fases pré-inicial, sendo retirado na fase inicial.

Para avaliação de desempenho, os animais foram pesados nos dias $0,14,28$ e 49, que correspondeu ao $21^{\circ}, 35^{\circ}, 49^{\circ}$ e $70^{\circ}$ dia de idade, coincidindo com cada troca de fase (e também de ração), quando foram computados o peso final (PF) na fase, consumo diário de ração (CDR), ganho diário de peso (GDP) e a conversão alimentar (CA).

Os preços dos ingredientes utilizados na elaboração das rações experimentais foram 
obtidos na região de Londrina - PR, no mês de maio de 2010, sendo milho, $\mathrm{R} \$ 0,30 / \mathrm{kg}$; farelo de soja, R\$ 0,58/kg; suplemento pré-inicial IR\$ $4,16 / \mathrm{kg}$, suplemento pré-inicial II R\$3,81/kg, suplemento inicial R\$2,96/kg e PSD comercial, $\mathrm{R} \$ 15,11 / \mathrm{kg}$. A viabilidade econômica da utilização dos diferentes programas nutricionais foi verificada, segundo Bellaver et al. (1985). Na seqüência, foi calculado o Índice de Eficiência Econômica (IEE) e o Índice de Custo Médio (IC), segundo Barbosa et al. (1992), segundo as fórmulas:

\section{$\mathrm{IEE}=\mathrm{MC} / \mathrm{CT} \times 100 ;$}

$\mathrm{IC}=\mathrm{CT} / \mathrm{MC} \times 100$, em que: $\mathrm{MC}=$ menor custo médio observado em ração por quilograma de peso vivo ganho entre os tratamentos;

$\mathrm{CT}=$ custo médio do tratamento considerado.

O delineamento experimental para a avaliação zootécnica foi em blocos casualizados (divididos em três blocos de acordo com o peso inicial dos animais), com quatro tratamentos, seis repetições por tratamento (seis baias com dois machos castrados e uma fêmea) e dois tempos. Cada baia composta por três animais foi definida como uma unidade experimental.

Foram realizadas coletas de sangue aos 35 dias de idade dos leitões e no último dia do período experimental, quando os animais tinham em média 70 dias de idade. As amostras de sangue foram coletadas por punção jugular, nas primeiras horas da manhã, e levadas imediatamente ao Laboratório de Patologia Clínica da Universidade Estadual de Londrina, onde foram realizados os hemogramas e as determinações de uréia plasmática.

A avaliação da freqüência de diarréia foi realizada diariamente por um observador, através da verificação direta da presença de fezes diarréica na baia e posterior identificação do animal. O número total de casos de diarréia foi determinado e avaliado pelo teste de qui-quadrado.
Os dados relativos aos tratamentos foram submetidos à análise de variância e Teste de Tukey para comparação de médias utilizando-se o programa SAEG (UFV, 1997).

\section{Resultados e Discussão}

Os resultados do desempenho zootécnico nas fases pré-inicial I, pré-inicial II, inicial, pré-inicial I + II e pré-inicial I+II+ inicial estão demonstrados na Tabela 2.

A diferença para o peso inicial $(\mathrm{P}<0,05)$ foi decorrente do delineamento experimental, estando prevista naturalmente.

Não houve diferença $(\mathrm{P}>0,05)$ entre os tratamentos para o CDR em nenhuma das fases. De maneira geral, notou-se bons níveis de consumo em todos os tratamentos e em todas as fases quando comparado com trabalhos realizados com dietas complexas oferecidas para leitões desmamados aos 21 dias de idade (MAHAN; LEPINE, 1991; QUADROS et al., 2002; BARBOSA et al., 2007). Assim, os consumos elevados observados podem ter sido decorrentes da presença de palatabilizantes, aromatizantes e da lactose, um nutriente que guarda boa palatabilidade e promove melhorias no desempenho (BERTOL; SANTOS FILHO; LUDKE, 2000) e de outros ingredientes de elevado valor nutritivo utilizados nas rações.

Segundo Figueiredo et al. (2003), uma alternativa para reduzir o desafio nutricional causado pelo desmame é o uso de dietas complexas contendo PSD como fonte de proteína de qualidade. Segundo Dritz (1994), o fornecimento de dietas complexas a leitões de creche promove uma melhora no desempenho, que se prolonga até o abate. Mahan e Lepine (1991), testando manejos nutricionais diferenciados para recuperar leitões leves ao desmame de 21 a 28 dias, verificaram que animais leves $(4,1$ a $5,0 \mathrm{~kg})$ respondem melhor a dietas complexas. 
Tabela 2. Médias e desvios das características de desempenho dos leitões em cada fase, no acumulado das fases pré-inicial I e II e no período experimental total.

\begin{tabular}{|c|c|c|c|c|c|c|}
\hline \multirow[t]{2}{*}{ Variáveis $^{1}$} & \multicolumn{4}{|c|}{ Tratamentos (peso inicial dos leitões/ oferta diária de PSD) } & \multirow[t]{2}{*}{$\mathbf{P}<$} & \multirow[t]{2}{*}{ CV\% } \\
\hline & Pesado / 0g & Leve / 10g & Leve / 20g & Leve / 0g & & \\
\hline \multicolumn{7}{|c|}{ Pré-inicial I } \\
\hline PI (kg) & $6,14 \pm 0,32 \mathrm{a}$ & $5,08 \pm 0,24 b$ & $5,06 \pm 0,23 \mathrm{~b}$ & $5,06 \pm 0,27 \mathrm{~b}$ & 0,000 & 2,63 \\
\hline $\mathrm{PF}(\mathrm{kg})$ & $8,17 \pm 0,49$ & $7,78 \pm 0,67$ & $7,93 \pm 0,36$ & $7,50 \pm 0,84$ & ns & 7,35 \\
\hline CDR $(g)$ & $255 \pm 70$ & $285 \pm 30$ & $290 \pm 30$ & $295 \pm 80$ & ns & 20,64 \\
\hline GDP $(g)$ & $147 \pm 50$ & $192 \pm 50$ & $205 \pm 20$ & $173 \pm 40$ & ns & 24,48 \\
\hline $\mathrm{CA}(\mathrm{g} / \mathrm{g})$ & $2,04 \pm 0,54$ & $1,69 \pm 0,34$ & $1,64 \pm 0,32$ & $2,05 \pm 0,77$ & ns & 24,22 \\
\hline \multicolumn{7}{|c|}{ Pré-inicial II } \\
\hline PF (kg) & $14,80 \pm 0,64$ & $14,59 \pm 1,11$ & $15,02 \pm 0,78$ & $14,43 \pm 2,26$ & ns & 8,83 \\
\hline CDR (g) & $767 \pm 60$ & $735 \pm 90$ & $718 \pm 50$ & $790 \pm 150$ & ns & 11,58 \\
\hline GDP (g) & $473 \pm 40$ & $488 \pm 40$ & $508 \pm 40$ & $493 \pm 100$ & ns & 11,93 \\
\hline $\mathrm{CA}(\mathrm{g} / \mathrm{g})$ & $1,62 \pm 0,15$ & $1,52 \pm 0,17$ & $1,42 \pm 0,12$ & $1,60 \pm 0,11$ & $\mathrm{~ns}$ & 8,47 \\
\hline \multicolumn{7}{|c|}{ Inicial } \\
\hline PF (kg) & $27,17 \pm 1,13$ & $26,50 \pm 2,04$ & $27,56 \pm 1,57$ & $27,06 \pm 3,90$ & ns & 7,33 \\
\hline CDR (g) & $1302 \pm 100$ & $1198 \pm 270$ & $1292 \pm 220$ & $1381 \pm 200$ & ns & 13,45 \\
\hline GDP (g) & $589 \pm 40$ & $567 \pm 50$ & $597 \pm 60$ & $601 \pm 90$ & ns & 7,94 \\
\hline $\mathrm{CA}(\mathrm{g} / \mathrm{g})$ & $2,22 \pm 0,28$ & $2,12 \pm 0,50$ & $2,19 \pm 0,49$ & $2,31 \pm 0,22$ & ns & 10,43 \\
\hline \multicolumn{7}{|c|}{ Pré-inicial I+II } \\
\hline $\mathrm{CDR}(\mathrm{g})$ & $483 \pm 40$ & $485 \pm 50$ & $483 \pm 20$ & $512 \pm 100$ & $\mathrm{~ns}$ & 12,46 \\
\hline GDP (g) & $310 \pm 20$ & $340 \pm 40$ & $357 \pm 30$ & $333 \pm 70$ & $\mathrm{~ns}$ & 13,83 \\
\hline $\mathrm{CA}(\mathrm{g} / \mathrm{g})$ & $1,56 \pm 0,07 \mathrm{a}$ & $1,43 \pm 0,09 \mathrm{ab}$ & $1,36 \pm 0,15 b$ & $1,52 \pm 0,09 \mathrm{a}$ & 0,01 & 7,13 \\
\hline \multicolumn{7}{|c|}{ Período total } \\
\hline CDR (g) & $858 \pm 50$ & $813 \pm 130$ & $848 \pm 110$ & $913 \pm 140$ & $\mathrm{~ns}$ & 11,86 \\
\hline GDP (g) & $430 \pm 20$ & $437 \pm 40$ & $458 \pm 20$ & $448 \pm 70$ & $\mathrm{~ns}$ & 9,36 \\
\hline $\mathrm{CA}(\mathrm{g} / \mathrm{g})$ & $2,01 \pm 0,16 \mathrm{a}$ & $1,86 \pm 0,26 b$ & $1,85 \pm 0,27 b$ & $2,04 \pm 0,10 \mathrm{a}$ & 0,05 & 6,92 \\
\hline
\end{tabular}

Letras diferentes na linha indicam diferença significativa pelo teste de Tuckey (5\%)

ns $=$ não significativo $(\mathrm{P}>0,05)$

${ }^{1} \mathrm{PI}=$ peso médio inicial; $\mathrm{PF}=$ peso médio final; $\mathrm{CDR}=$ consumo diário de ração; $\mathrm{GDP}=$ ganho diário de peso; $\mathrm{CA}=$ conversão alimentar;

Fonte: Elaboração dos autores.

Portanto, a dimensão das respostas ao uso do PSD como ingrediente em rações para leitões desmamados é dependente da composição da dieta. Em experimentos onde a soja constituiu a principal fonte protéica da dieta, as respostas para o desempenho foram melhoradas com a inclusão do PSD (VAN DIJK et al., 2001).

Apesar do CDR não ter sido diferente entre os tratamentos, foi observado que os animais que receberam dietas com $10 \mathrm{~g}$ e $20 \mathrm{~g}$ por dia de PSD apresentaram $12 \%$ e $14 \%$, respectivamente, maior consumo. A alta palatabilidade do PSD pode ter colaborado com este resultado (HANSEN et al., 1993; COFFEY; CROMWELL, 1995; KATS; TOKACH; NELSSEN, 1992; BARBOSA et al., 2007; GATTÁS et al., 2008). Barbosa et al. (2007), avaliando o melhor nível de inclusão do PSD para leitões desmamados aos 21 dias de 
idade, determinaram em 4,3, 2,5 e 1,3\% a inclusão de PSD na dieta na primeira, segunda e terceira semana pós-desmame, respectivamente.

Apesar de não haver mudança na inclusão da quantidade PSD diariamente nos tratamentos 2 e 3, houve uma redução gradual do percentual de plasma consumido para cada animal, pois a ingestão de ração progressivamente aumentou com o crescimento dos mesmos. Os resultados obtidos apontaram que o consumo diário de PSD para o tratamento 2 foi, em média, 3,5 e 1,5\% do consumo nas fases pré-inicial I e pré-inicial II, e de 6,9 e 3,0\%, em média para o tratamento 3 , nas fases pré-inicial I e pré-inicial II, respectivamente. No presente trabalho houve uma identificação com os níveis propostos por Barbosa et al. (2007) para o uso do PSD para leitões desmamados.

Contrário aos resultados observados, Rantanen et al. (1994) reportaram aumentos lineares no CDR alimentando leitões durante duas semanas pós-desmame com dietas contendo 0, 2, 4, ou 6\% de PSD. Koehler, Shurson e Whitney (1998) testaram 4\% de PSD dos dias 0 a 14 pós-desmame e verificaram um aumento do CDR nos 14 dias pós-desmame quando comparado a uma dieta controle. Segundo Hansen et al. (1993), até 7 ou 14 dias pós-desmame, a participação do PSD resultou em maior consumo de ração comparado com leitões que receberam dieta com leite em pó. Após os 14 dias até os 35 dias pós-desmame, houve a manutenção do maior consumo a favor do grupo tratado com ração com PSD.

Para o GDP não houve diferença $(\mathrm{P}>0,05) \mathrm{em}$ nenhum dos períodos, contrariando os resultados obtidos em vários trabalhos (HANSEN et al., 1993; RANTANEN et al., 1994; SMITH II et al., 1995; LINDEMANN et al., 1998; PIERCE et al., 2005; TUCKER, 2007). No entanto, Guzik et al. (2002), alimentando leitões com 1,5\% de PSD, por 8 dias após o desmame, observaram uma redução no consumo, no ganho de peso e piora da conversão alimentar. Van Dijk et al. (2002a), fornecendo
3,0\% de PSD não encontraram nenhuma diferença no CDR, GDP e CA entre os dias 0 e 7, mas observaram melhora desses índices no intervalo entre os dias 8 e 21 e entre 0 e 21 . Possivelmente a complexidade da dieta utilizada neste trabalho e sua identificação com o status fisiológico e enzimático dos leitões foram suficientes para promover um GDP semelhante aos animais pesados, sendo que o PSD não interferiu nesta variável.

Os valores de CA apresentaram diferença $(\mathrm{P}<0,01$ e $\mathrm{P}<0,05)$ nas fases pré-inicial $\mathrm{I}+\mathrm{II}(21$ a 49 dias de idade) e no período experimental total (21 a 70 dias de idade), respectivamente, demonstrando um melhor aproveitamento das dietas 2 e 3 ( $10 \mathrm{~g}$ e $20 \mathrm{~g}$ de PSD por animal por dia, respectivamente) entre os 21 e 49 dias de idade. Esta melhora no parâmetro foi mantida até o fim do período experimental. Esses resultados foram semelhantes aos encontrados por vários autores (HANSEN et al., 1993; COFFEY; CROMWELL, 1995; 2001; SMITH II et al., 1995; GATTÁS et al., 2008; ASSIS JÚNIOR et al. 2009). No entanto, na maioria dos trabalhos encontrramse diferenças significativas também na primeira semana pós-desmame, diferindo dos resultados obtidos. Segundo Van Dijk et al. (2001), para a CA, os melhores níveis de inclusão de PSD devem ser de no máximo $6 \%$, sendo que níveis maiores apresentam respostas variáveis. Pesquisas com leitões desmamados aos 21 dias de idade indicam que o uso de PSD aumenta a secreção das enzimas digestivas, melhora a integridade do epitélio intestinal e melhora a digestão, absorção e utilização dos nutrientes, especialmente na primeira semana após o desmame, aos 21 dias de idade (CAMPBELL, 2003).

Coffey e Cromwell (1995) relacionaram as imunoglobulinas presentes no plasma à melhora no desempenho dos animais após o desmame, visto que essas imunoglobulinas podem prevenir os danos causados por patógenos à parede intestinal, mantendo as características digestivas e absortivas do intestino. 
Com relação ao peso final nas fases, não houve diferença entre os tratamentos $(\mathrm{P}>0,05)$, mostrando uma recuperação do desempenho dos animais leves ao desmame. O peso médio final dos animais do tratamento 4 indicam que estes apresentaram desempenho semelhantes aos animais dos tratamentos 2 e 3, sugerindo que a adição de PSD na ração não interferiu nesta característica. Segundo Touchette, Allee e Newcomb (1996), dietas contendo PSD poderiam demonstrar resultados semelhantes a dietas isentas do ingrediente, quando estas são complexas. Também relataram que com a retirada o $\mathrm{PSD}$, à medida que os animais passam para fases mais tardias, pode ocorrer uma redução no consumo, fazendo com que o grupo venha a apresentar um desempenho equivalente ao grupo que não recebeu o PSD. Um quadro semelhante pode ter sido observado neste trabalho, onde os leitões leves, diante de uma dieta de boa qualidade e com condições de acesso fácil ao cocho, mesmo sem a adição de PSD (tratamento 4), apresentaram bom desempenho, igualando os resultados dos demais tratamentos. Kats et al. (1994) observaram queda no ganho de peso nos 14 dias após a retirada do plasma da dieta, no entanto, o consumo de ração e a conversão alimentar não foram afetadas. Contrário aos resultados obtidos, Hansen et al. (1993) verificaram que níveis crescentes de PSD nas primeiras semanas após o desmame melhoram o ganho de peso no período subseqüente à sua retirada da dieta. Relataram ainda que leitões alimentados com PSD apresentaram melhores resultados nas duas primeiras semanas pós-desmame e pior desempenho nas semanas seguintes.

Os resultados de hemograma realizado aos 35 dias de idade e aos 70 dias de idade dos animais estão demonstrados na Tabela 3 .

Somente para os valores de uréia plasmática aos 35 dias de idade foi observado diferença $(\mathrm{P}<0,01)$ entre os tratamentos. Os animais leves ao desmame mostraram valores inferiores aos animais pesados e posteriormente, aos
70 dias de vida, os valores não apresentaram diferença significativa. Esses resultados sugerem possivelmente uma baixa ingestão de proteína e/ ou pior aproveitamento da proteína dietética em relação aos animais pesados ao desmame, o que em parte explicaria o pior desempenho desses animais na fase de maternidade. A concentração de uréia plasmática está positivamente relacionada com a taxa de síntese de uréia e, portanto, inversamente relacionada com a eficiência de deposição de nitrogênio ou tecido muscular.

A quantidade de nitrogênio ingerido (consumo de ração) também tem uma relação positiva com as concentrações de uréia plasmática e, ainda, o consumo excessivo de proteína aumenta a síntese e a excreção de uréia, refletindo no incremento da uréia (EGGUM, 1970). O mesmo autor relatou que a concentração de uréia plasmática está inversamente relacionada com a utilização da proteína dietética e reflete a magnitude da degradação de aminoácidos.

Os resultados da freqüência de diarréia não apresentaram diferença $(\mathrm{P}>0,05)$, sendo semelhantes aos encontrados por Van Dijk et al. (2002b), que trabalharam com dois grupos de leitões desmamados desafiados com E. coli recebendo uma dieta à base de soro de leite e farelo de soja e o outro com inclusão de $8 \%$ de PSD.

A utilização do PSD para leitões desmamados reduz a incidência e a gravidade da diarréia em leitões (VAN DER PEET, SCHWERING; BINNENDIJK, 1995; OWUSU-ASIEDU et al., 2000), sendo estes mais pronunciados em ambientes de baixo padrão sanitário (COFFEY; CROMWELL, 1995), fato que pode explicar a ausência de vantagem para as dietas que continham PSD, dada a qualidade do ambiente experimental utilizado.

Os resultados calculados para avaliação econômica estão demonstrados na Tabela 4. 
Tabela 3. Médias e desvios dos valores de hemograma dos leitões leves e pesados ao desmame e suplementados com plasma sanguíneo desidratado (PSD), aos 35 e 70 dias de idade.

\begin{tabular}{|c|c|c|c|c|c|c|}
\hline \multirow[t]{2}{*}{ Variáveis $^{1}$} & \multicolumn{4}{|c|}{ Tratamentos (peso inicial dos leitões/ oferta diária de PSD) } & \multirow[t]{2}{*}{$\mathbf{P}<$} & \multirow[t]{2}{*}{ CV $(\%)$} \\
\hline & Pesado / 0g & Leve / 10g & Leve / 20g & Leve / 0g & & \\
\hline \multicolumn{7}{|c|}{35 dias de idade } \\
\hline$\overline{\mathrm{HT}}(\%)$ & $37,57 \pm 3,41$ & $39,20 \pm 4,97$ & $38,60 \pm 4,22$ & $34,60 \pm 2,41$ & ns & 9,40 \\
\hline $\mathrm{HB}(\mathrm{g} / \mathrm{dl})$ & $12,56 \pm 1,35$ & $12,80 \pm 2,29$ & $12,12 \pm 2,20$ & $11,28 \pm 0,72$ & ns & 12,49 \\
\hline $\mathrm{HE}\left(\mathrm{mm}^{3}\right)$ & $8,05 \pm 0,16$ & $8,34 \pm 1,18$ & $7,88 \pm 0,77$ & $7,27 \pm 0,14$ & ns & 9,75 \\
\hline Leucocitos $\left(\mathrm{mm}^{3}\right)$ & $11942 \pm 5011$ & $12790 \pm 2816$ & $15020 \pm 2805$ & $12470 \pm 3928$ & ns & 30,91 \\
\hline PTP (g/dl) & $5,03 \pm 0,24$ & $5,40 \pm 0,58$ & $5,36 \pm 0,22$ & $5,08 \pm 0,39$ & ns & 7,37 \\
\hline Segmentados $(\%)$ & $43,86 \pm 15,09$ & $46,40 \pm 5,77$ & $46,80 \pm 11,78$ & $45,60 \pm 16,07$ & ns & 23,89 \\
\hline Plaquetas $\left(\mathrm{mm}^{3}\right) 3$ & $375000 \pm 165151$ & $437500 \pm 77629$ & $459000 \pm 116318$ & $473000 \pm 96726$ & ns & 24,28 \\
\hline Linfócitos $(\%)$ & $54,43 \pm 14,85$ & $52.20 \pm 4,97$ & $50,40 \pm 12,30$ & $47,25 \pm 15,67$ & ns & 19,88 \\
\hline Uréia (mg/dl) & $23,36 \pm 4,92 \mathrm{a}$ & $15,78 \pm 4,97 b$ & $16,20 \pm 7,43 b$ & $20,88 \pm 4,90 \mathrm{ab}$ & 0,01 & 25,15 \\
\hline \multicolumn{7}{|c|}{70 dias de idade } \\
\hline HT (\%) & $41,50 \pm 2,56$ & $41,71 \pm 1,97$ & $41,71 \pm 1,25$ & $42,37 \pm 1,68$ & ns & 4,24 \\
\hline $\mathrm{HB}(\mathrm{g} / \mathrm{dl})$ & $14,25 \pm 0,94$ & $13,92 \pm 0,55$ & $13,89 \pm 0,51$ & $14,21 \pm 0,62$ & ns & 4,96 \\
\hline $\mathrm{HE}\left(\mathrm{mm}^{3}\right)$ & $7,88 \pm 1,57$ & $7,71 \pm 1,51$ & $7,72 \pm 1,35$ & $7,87 \pm 1,49$ & ns & 4,23 \\
\hline Leucocitos $\left(\mathrm{mm}^{3}\right)$ & $9928 \pm 2299$ & $29192 \pm 47906$ & $12615 \pm 2606$ & $11706 \pm 4094$ & ns & 145,48 \\
\hline PTP (g/dl) & $6,10 \pm 0,47$ & $5,97 \pm 0,14$ & $6,14 \pm 0,25$ & $6,02 \pm 0,43$ & ns & 4,65 \\
\hline Segmentados $(\%)$ & $28,00 \pm 13,55$ & $33,86 \pm 12,05$ & $29,00 \pm 13,07$ & $30,57 \pm 7,85$ & ns & 36,23 \\
\hline Plaquetas $\left(\mathrm{mm}^{3}\right)$ & $630666 \pm 221153$ & $615857 \pm 118042$ & $650143 \pm 40977$ & $7 \quad 642000 \pm 150436$ & ns & 22,34 \\
\hline Linfócitos (\%) & $64,37 \pm 16,93$ & $62,86 \pm 11,26$ & $70,43 \pm 14,87$ & $64,50 \pm 6,59$ & ns & 19,70 \\
\hline Uréia (mg/dl) & $23,21 \pm 4,91$ & $23,61 \pm 6,07$ & $27,78 \pm 5,91$ & $25,83 \pm 4,55$ & ns & 21,64 \\
\hline
\end{tabular}

Letras diferentes na linha indicam diferença significativa pelo teste de Tuckey (5\%)

ns $=$ não significativo $(\mathrm{P}>0,05)$

$1 \mathrm{HT}=$ hematócrito; $\mathrm{HB}=$ hemoglobina; $\mathrm{HE}=$ hemácias; $\mathrm{PTP}=$ proteínas totais plasmáticas

Fonte: Elaboração dos autores.

Observou-se, de acordo com as condições experimentais e dos preços dos ingredientes obtidos no período, que os melhores índices de eficiência econômica e de custo médio foram verificados para o tratamento com inclusão de $20 \mathrm{~g}$ de PSD por animal por dia nas fases pré-inicial I e II, separadamente e juntas, e no período total. A fase pré-inicial I apresentou os maiores custos em ração devido ao alto valor dos ingredientes utilizados. Entre os tratamentos foi observado menor custo em ração para os tratamentos constituídos por animais leves ao desmame, com destaque para o tratamento com $20 \mathrm{~g}$ de PSD, devido à melhor relação entre consumo e ganho de peso. No segundo período os custos sofreram uma redução devido à menor complexidade da dieta e também aos bons resultados de CA obtidos por todos os tratamentos.
Já no terceiro período os custos mantiveram a tendência de redução devido à menor quantidade e complexidade dos ingredientes constituintes da ração. Neste período o tratamento com $10 \mathrm{~g}$ de PSD mostrou o melhor índice de eficiência econômica e de custo médio devido à melhor CA dos animais. Levando-se em consideração todo o período de fornecimento do PSD (fase préinicial I + II), novamente o tratamento com $20 \mathrm{~g}$ de PSD apresentou os menores custos, sendo que os tratamentos dispensados aos animais pesados e leves sem suplementação apresentaram resultados semelhantes e aquém do grupo que recebeu a inclusão de $10 \mathrm{~g}$ de PSD. Ao analisar o período experimental como um todo, os resultados mostraram que os leitões do tratamento com $20 \mathrm{~g}$ de PSD suplementar apresentaram resultados economicamente melhores que os demais. 
Tabela 4. Custo médio de ração por quilograma de peso vivo ganho (R $\$ / \mathrm{kg} P V)$, índice de eficiência econômica (IEE) e índice de custo médio (ICM) de acordo com os tratamentos experimentais.

\begin{tabular}{|c|c|c|c|c|}
\hline \multirow[t]{2}{*}{ Variáveis $^{1}$} & \multicolumn{4}{|c|}{ Tratamentos (peso inicial dos leitões/ oferta diária de PSD) } \\
\hline & Pesado / 0g & Leve / 10g & Leve / 20g & Leve / 0g \\
\hline & \multicolumn{4}{|c|}{ Pré-inicial I } \\
\hline Custo & 3,28 & 2,81 & 2,68 & 3,23 \\
\hline $\operatorname{IEE}(\%)$ & 77,38 & 95,07 & 100,00 & 79,46 \\
\hline \multirow[t]{2}{*}{$\mathrm{ICM}(\%)$} & 122,62 & 104,93 & 100,00 & 120,54 \\
\hline & \multicolumn{4}{|c|}{ Pré-inicial II } \\
\hline Custo & 2,02 & 1,88 & 1,76 & 2,00 \\
\hline $\operatorname{IEE}(\%)$ & 85,27 & 93,44 & 100,00 & 86,62 \\
\hline \multirow[t]{2}{*}{$\operatorname{ICM}(\%)$} & 114,73 & 106,56 & 100,00 & 113,38 \\
\hline & \multicolumn{4}{|c|}{ Inicial } \\
\hline Custo & 1,08 & 1,04 & 1,06 & 1,13 \\
\hline $\operatorname{IEE}(\%)$ & 95,38 & 100,00 & 97,57 & 91,25 \\
\hline \multirow[t]{2}{*}{ ICM (\%) } & 104,62 & 100,00 & 102,43 & 108,75 \\
\hline & \multicolumn{4}{|c|}{ Pré-inicial I+II } \\
\hline Custo & 2,32 & 2,14 & 2,03 & 2,32 \\
\hline $\operatorname{IEE}(\%)$ & 85,40 & 94,29 & 100,00 & 85,58 \\
\hline \multirow[t]{2}{*}{$\operatorname{ICM}(\%)$} & 114,60 & 105,71 & 100,00 & 114,42 \\
\hline & \multicolumn{4}{|c|}{ Período total } \\
\hline$\overline{\text { Custo }}$ & 1,72 & 1,64 & 1,59 & 1,75 \\
\hline $\operatorname{IEE}(\%)$ & 91,66 & 96,68 & 100,00 & 89,49 \\
\hline ICM (\%) & 108,34 & 103,32 & 100,00 & 110,51 \\
\hline
\end{tabular}

Fonte: Elaboração dos autores.

\section{Conclusões}

A adição de plasma sanguíneo desidratado diretamente no cocho, nas quantidades utilizadas, não promoveu melhora no desempenho de leitões leves em comparação a leitões pesados, desmamados aos 21 dias de idade. Houve melhora no aproveitamento da dieta pelos animais leves, observado pelo nível de uréia plasmática e melhor CA no tratamento com adição de $20 \mathrm{~g}$ de PSD nas fases pré-inicial I+II.

A utilização do PSD não influenciou no aparecimento de diarréia. A adição de $20 \mathrm{~g}$ de PSD, durante 28 dias pós-desmame, apresentou a melhor viabilidade econômica, repercutindo em todo o período de creche.

\section{Referências}

ASSIS JÚNIOR, F. I.; FERREIRA, A. S.; DONZELE, J. L.; DETMANN, E.; BARBOSA, F. F.; SOUZA JUNIOR, A. H. Níveis de plasma sanguíneo em dietas pós-desmame para leitões desmamados aos 28 dias de idade. Revista Brasileira de Zootecnia, Viçosa, MG, v. 38, n. 5, p. 843-849, 2009.

BARBOSA, F. F.; FERREIRA, A. S.; GATTÁS, G.; SILVA, F. C. de O.; DONZELE, J. L.; BRUSTOLINI, P. C.; LOPES, D. C. Níveis de plasma sanguíneo em pó em dietas para leitões desmamados aos 21 dias de idade. Revista Brasileira de Zootecnia, Viçosa, MG, v. 36, n. 4, p. 1052-1060, 2007.

BARBOSA, H. P.; FIALHO, E. T.; FERREIRA, A. S.; LIMA, G. J. M. M.; GOMES, M. F. M. G. Triguilho para suínos nas fases inicial de crescimento, crescimento e terminação. Revista Brasileira de Zootecnia, Viçosa, MG, v. 21, n. 5, p. 827-837, 1992.

BELlAVER, C.; FIALHO, E. T.; PROTAS, J. F. S.; 
GOMES, P. C. Radícula de malte na alimentação de suínos em crescimento e terminação. Pesquisa Agropecuária Brasileira, Brasília, v. 20, n. 8, p. 969-974, 1985.

BERTOL, T. M.; SANTOS FILHO, J. I.; LUDKE, J. V. Níveis de suplementação com lactose na dieta de leitões desmamados. Revista Brasileira de Zootecnia, Viçosa, MG, v. 29, n. 5, p. 1387-1393, 2000.

CAMPBELL, J. M. Use of plasma in swine feeds. 2003. Disponível em: <http://www.americanprotein.com/ discoveres/summer98/plasma.html. Acesso em: 20 maio 2010.

COFFEY, R. D.; COMWELL, G. L. The impact of environment and antimicrobial agents on the growth response of early weaned pigs to spray-dried porcine plasma. Journal of Animal Science, Madison, v. 73, n. 9, p. 2532-2539, 1995.

CROMWELL, G. L. Rendered products in swine nutrition. In: MEEKER, D. L. National renderers association, essential rendering. Airlington: Kirby, 2006, p. 141-157.

DALTON, O. F.; SOUZA, L. P. O.; SALUM, G. M. Como alimentar porcas que desmamam 30 leitões por ano. In: SIMPÓSIO SOBRE MANEJO E NUTRIÇÃO DE AVES E SUÍNOS, 70., 2008, Campinas. Anais... Campinas: CBNA, 2008, p. 129-158.

DEPRÉZ, P.; NOLLET, H.; VAN DRIESSCHE, E.; MUYLLE, E. The use of swine plasma components as adhesin inhibitors in the protection of piglets against Escherichia coli enterotoxemia. In: IPVS CONGRESS, 14., 1996, Bologna. Proceeeding... Bologna: International Pig Veterinary Society Congress, 1996, p. 276.

DRITZ, S. Management to optimize productivity of the weaned pig. In: LONDON SWINE CONFERENCE, 1; 2., 2004, London. Proceeding...London: London Swine Conference, 2004. p. 7-18.

EGGUM, B. O. Blood urea measurement as a technique for assessing protein quality. British Journal of Nutrition, United Kingdom, v. 24, n.4, p. 983, 1970.

FIGUEIREDO, A. N.; MIYADA, V. S.; UTIYAMA, C. E.; LONGO, F. A. Ovo em pó na alimentação de leitões recém-desmamados. Revista Brasileira de Zootecnia, Viçosa, MG, v. 32, n. 6, p. 1901-1911, 2003.

GATTÁS, G.; FERREIRA, A. S.; BARBOSA, F. F.; SILVA, F. C. O.; DONZELE, J. L.; LOPES, D. C. Plasma Sanguíneo em pó em dietas para leitões desmamados aos 14 dias de idade. Revista Brasileira de Zootecnia, Viçosa, MG, v. 37, n. 2, p. 278-285, 2008.

GUZIK, A. C.; SOUTHERN, L. L.; BIDNER, T. D.;
KERR, B. J. The tryptophan requirement of nursery pigs. Journal of Animal Science, Madison, v. 80, n. 10, p. 2646-2655, 2002.

HANSEN, J. A.; NELSSEN, J. L.; GOODBAND, R. D.; WEEDEN, T. L. Evaluation of animal protein supplements in diets of early-weaned pigs. Journal of Animal Science, Madison, v. 71, n. 7, p. 1853-1862, 1993.

HOLANDA, M. C. R.; BARBOSA, S. B. P.; SAMPAIO, I. B. M.; SANTOS, E. S.; SANTORO, K. R. Tamanho da leitegada e pesos médios, ao nascer e aos 21 dias de idade, de leitões da raça Large White. Arquivo Brasileiro de Medicina Veterinária e Zootecnia, Belo Horizonte, v. 57, n. 4, p. 539-544, 2005.

KATS, L. J.; TOKACH, J.; NELSSEN, J. L. Optimum level of spray-dried blood meal in phase II diet. In: SWIENE DA, 1992, Manhattan, KS. Anais...Manhattan: Kansas State University. Agricultural Experiment Station and Cooperative Extension Service, 1992, p. 27-29.

KATS, L. J.; NELSSEN, J. L.; TOKACH, M. D.; GOODBAND, R. D.; HANSEN, J. A.; LAURIN, J. L. The effect of spray-dried porcine plasma on growth performance in the early-weaned pig. Journal of Animal Science, Madison, v. 72, n. 8, p. 2075-2081, 1994.

KOEHLER, D. D.; SHURSON, G. C.; WHITNEY, M. H. Effect of spray dried porcine solubles, with and without spray dried plasma, on growth performance of weaned pigs. Journal of Animal Science, Madison, v. 76, p. 180, 1998. Suplemento.

LE DIVIDICH, J. A. Review - neonatal and weaner pig: management to reduce variation. In: CRANWELL, P. D. (Ed.). Manipulating pig production VII. Werribee, Victoria, Australia: Australian Pig Sicence Association, p. 135-156, 1999.

LINDEMANN, M. D.; VAN LIGT, J. L. G.; MONEGUE, H. J.; KELLER, G.; CROMWELL, G. L. Evaluation of dried porcine solubles (DPS) as a feed ingredient for weanling pigs. Journal of Animal Science, Madison, v. 76, p. 181, 1998. Suplemento.

MAHAN, D. C.; LEPINE, A. J. Effect of pig weaning weight and associated nursery feeding programs on subsequent performance to 105 kilograms body weight. Journal of Animal Science, Madison, v. 69, n. 4, p. 13701378, 1991.

MAKKINK, C. A.; NEGULESCU, G. P.; GUIXIN, Q.; VERSTEGEN, M. W. A. Effects of dietary protein source on feed intake, growth pancreatic enzyme activities and jejunal morphology in newly weaned piglets. British Journal of Nutrition, United Kingdom, v. 72, n. 3, p. 353$368,1994 b$. 
MAKKINK, C. A.; BERNTSEN, P. J.; OP DEN KAMP, B. M.; KEMP, B.; VERSTEGEN, M. W. Gastric protein breakdown and pancreatic enzyme activities in response to two different dietary protein source in newly weaned pigs. Journal of Animal Science, Madison, v. 72, n. 11, p. 2843-2850, 1994a.

MORÉS, N. Fatores que limitam a produção de leitões na maternidade. Concórdia: EMBRAPA - CNPSA, 1993, 5 p. (Suinocultura dinâmica, n. 9).

NOLLET, H.; DEPREZ, P.; VAN DRIESSCHE, E.; MUYLLE, E. Protection of just weaned pigs against infection with $\mathrm{F} 18+$ Escherichia coli by non-immune plasma powder. Veterinary Microbiology, Barcelona, Spain, v. 65, n. 1, p. 37-45, 1999.

OWUSU-ASIEDU, A.; MARQUARDT, R. R.; BAIDOO, S. K.; FROHLICH, A. A.; NYACHOTI, C. M.; CHO, S. H. Spray-dried porcine plasma (SDPP): therapeutic antibody against enterotoxigenic $E$. coli in early-weaned pig. Canadian Journal of Animal Science, Madison, v. 80, p. 756, 2000. Abstract.

PEINIAU, J.; AUMAITRE, A.; LEBRETON, Y. Effects of dietary protein sources differing in solubility on total tract and ileal apparent digestibility of nitrogen and pancreatic enzymes activity in early weaned pigs. Livestock Production Science, Amsterdam, v. 45, n. 2-3, p. 197-208, 1996.

PIERCE, J. L.; CROMWELL, G. L.; LINDEMANN, M. D.; RUSSELL, L. E.; WEAVER, E. M. Effects of spray-dried animal plasma and immunoglobulins on performance of early weaned pigs. Journal of Animal Science, Madison, v. 83, n. 12, p. 2876-2885, 2005.

QUADROS, A. R. B.; CHARLES, K.; HENN, J. D.; SCARIOT, G.; SILVA, J. H. S. Dietas simples e complexas sobre o desempenho de leitões na fase de creche. Ciência Rural, Santa Maria, v. 32, n. 1, p. 109114, 2002.

RANTANEN, M. M.; NELSSEN, J. L.; GOODBAND, R. D.; TORACH, M. D.; SMITH, J. W. II; RICHERT, B.T.; FRIESEN, K. G.; RUSSELL, L.E. Influence of spray-dried plasma source on growth performance of weanling pigs. Journal of Animal Science, Madison, v. 77, p. 166, 1994. Suplemento.

SMITH II, J. W.; RICHERT, B. T.; NELSSEN, J. L.; GOODBAND, R. D.; TOKACH, M. D. The effect of spray-dried plasma source on starter pig performance. Journal of Animal Science, Madison, v. 73, p. 80, 1995. Suplemento.

TOUCHETTE, K. J; ALLEE, G. L.; NEWCOMB, M. D. The effects of plasma, lactose and soil protein sources fed in a phase 1 diet on nursery performance.
Journal of Animal Science, Madison, v. 74, p. 170, 1996. Suplemento 1.

TUCKER, J. The effects of various feed additives on growth performance of nursery pigs. 2007. Dissertação (Mestrado em Ciência Animal) - Louisiana State University, Louiseana.

UNIVERSIDADE FEDERAL DE VIÇOSA - UFV. Sistema de análises estatísticas e genéticas - SAEG. Viçosa, MG: UFV, 1997. p. 150.

VAN DER PEET-SCHWERING, C. M. C.; BINNENDIJK, G. P. The effect of spray-dried porcine plasma in diets with diferent protein sources on the performance of weanling piglets. Praktijkkonder-zoek Vankenshouderij, Rosmalen, The Netherlands, n. 1, p. 137, 1995.

VAN DIJK, A. J.; MARGRY, R. J. C. F.; VAN DER LEE, A. G.; HEMKE, G.; BEYNEN, A. C. Growth performance and health status in weanling piglets fed spray-dried porcine plasma under typical Northern European conditions. Journal of Physiology and Animal Nutrition, Oxford, v. 86, n. 1-2, p. 17-25, 2002a.

VAN DIJK, A. J.; EVERTS, H.; NABUURS, M. J. A.; MARGRY, R. J. C. F.; BEYNEN, A. C. Growth performance of weanling pigs fed spray-dried animal plasma: a review. Livestock Production Science, Amsterdam, v. 68, n. 2-3, p. 263-274, 2001.

VAN DIJK, A. J.; ENTHOVEN, P. M. M.; VAN DEN HOVEN, S. G. C.; VAN LAARHOVEN, M. M. M. H.; NIEWOLD, T. A.; NABUURS, M. J. A.; BEYNEN, A. $\mathrm{C}$. The effect of dietary spray-dried porcine plasma on clinical response in weaned piglets challenged with a pathogenic Escherichia coli. Veterinary Microbiology, Barcelona, Spain, v. 84, n. 3, p. 207-218, 2002 b. 